ORIGINAL ARTICLE

\title{
Infection, health problems, and health care utilisation, and the risk of sudden infant death syndrome
}

\author{
M M T Vennemann, M Findeisen, T Butterfaß-Bahloul, G Jorch, B Brinkmann, W Köpcke, \\ T Bajanowski, A Richter, E A Mitchell, the GeSID Group
}

Arch Dis Child 2005;90:520-522. doi: 10.1136/adc.2004.065581

\begin{abstract}
See end of article for authors' affiliations

.....................

Correspondence to:

Dr M Vennemann, Institute of Epidemiology and

Social Medicine, University

of Münster, Domagkstr, 3, 48129 Münster, Germany; vennemam@uni-muenster. de
\end{abstract}

Accepted 28 January 2005
Aim: To examine whether symptoms suggestive of infection, health problems, and health care utilisation are risk factors for SIDS.

Methods: Matched case-control study with 333 SIDS infants and 998 control infants matched for region, age, gender, and reference sleep. Information was obtained by parental interview, paediatrician completed questionnaire, and hospital admission data.

Results: No symptoms were associated with SIDS after adjustment for potential confounders. Illness in the last four weeks as reported by the paediatrician did not differ between cases and controls. Developmental problems and special investigations at any stage of life significantly increased the risk of SIDS (adjusted $\mathrm{OR}=2.14$ and 2.07). Admission to hospital after the first week of life was associated with an increased risk of SIDS (adjusted OR $=1.88$ ).

Conclusion: Symptoms of infection and illness are no longer risk factors for SIDS in communities such as Germany where few infants sleep prone. The increased risk of SIDS with developmental problems may indicate that infants which subsequently die of SIDS are abnormal or in some way vulnerable.
$\mathrm{R}$ espiratory tract infection at postmortem examination is commonly seen in infants who die suddenly and unexpectedly. ${ }^{1-3}$ When the amount of infective change is not thought to be sufficient to cause the death it will be certified as sudden infant death syndrome (SIDS). Although symptoms suggestive of infection are common in normal infants, there is evidence that these symptoms are even more common in infants that die from SIDS. ${ }^{4}$ However, one small study found that infection was only a risk factor for SIDS among infants sleeping prone. ${ }^{5}$ Now that few infants sleep prone, we hypothesise that infection is no longer a risk factor for SIDS.

The aim of this study is to examine whether symptoms suggestive of infection, health problems, and health care utilisation are risk factors for SIDS in a population in which few infants sleep prone.

\section{METHODS}

The German SIDS case-control study has been described in detail previously. ${ }^{6}$ It was a large population based study of infants who died of SIDS between 8 days of age and completion of their first year of life (post-perinatal deaths) in the period November 1998 to October 2001. In the study area approximately $50 \%$ of all births in Germany occur. All cases underwent postmortem examination by forensic pathologists, in 18 institutes of forensic pathology which participated in the study, according to a standardised protocol. There were 404 SIDS cases; 333 (82.4\%) were interviewed.

For each case, 10 controls were selected that were matched for region, age, gender, and reference sleep. The control infants were recruited through the same or neighbouring local birth registration office where the case was registered. Control infants had been born 4-6 weeks after the case infant, so that by the time the interviews were done they had the same age as the index case $( \pm 2$ weeks). From the control families who agreed, the three infants closest in age to the index case were selected. A total of 2702 controls were contacted; $58.7 \%$ agreed to participate.
A structured questionnaire was administered to parents by trained interviewers. Information was obtained on symptoms during the last day and the previous seven days by parental interview. In addition, whether the parent had measured the child's temperature, and whether it was greater than $38^{\circ} \mathrm{C}$ was recorded. The infant's paediatrician completed an extensive questionnaire which also contained questions on illnesses in the last four weeks and specific health problems at any stage of life. Immunisations will be reported in detail separately. Hospital records were also examined to determine whether or not the infant had been admitted to hospital, and if so, whether it was for a respiratory infection.

This analysis used 333 SIDS infants and 998 matched control infants. Univariate analysis and multivariate analysis were performed using conditional logistic regression. ${ }^{8}$ Each variable that was statistically significant $(p<0.05)$ in the univariate analysis was included separately in a multivariate model that adjusted for maternal factors (age, family status, smoking in pregnancy, parity, and socioeconomic status), infant factors (birth weight), and postnatal factors (breast feeding for $>2$ weeks, sleep position, pacifier, and infant sharing a bed with an adult). The definitions of these variables have been described previously. ${ }^{7}$

All 18 centres had the approval of their local medical ethics committees, and the state data protection officer gave permission to recruit controls in each federal state.

\section{RESULTS}

Symptoms during the last day and in the previous seven days were common in both cases and controls (table 1 ). Respiratory symptoms did not increase the risk of SIDS; diarrhoea and vomiting (during the last day) and vomiting (during the last seven days) increased the risk of SIDS in the univariate analysis, but after adjustment for potential confounders were not associated with a statistically significant increased risk of SIDS. Documented fever $\left(>38^{\circ} \mathrm{C}\right)$ did not differ between cases and controls during the last day or the last seven days. Attendance at the doctor's surgery during 
Table 1 Symptoms, illnesses, health problems, and hospitalisation, and risk of SIDS

\begin{tabular}{|c|c|c|c|c|}
\hline Variable $(\mathrm{n}=$ missing) & Case, $\mathrm{n}(\%)$ & Control, n (\%) & Univariate OR $(95 \% \mathrm{Cl})$ & Multivariate ${ }^{*}$ OR $(95 \% \mathrm{Cl})$ \\
\hline \multicolumn{5}{|l|}{ In the last 7 days (parental interview) } \\
\hline Runny nose $(n=4)$ & $115(34.7)$ & $334(33.5)$ & $1.07(0.81$ to 1.39$)$ & \\
\hline Cough $(n=4)$ & 60 (18.2) & $173(17.4)$ & $1.07(0.77$ to 1.50$)$ & \\
\hline Diarrhoea $(n=8)$ & $28(8.6)$ & $65(6.5)$ & $1.37(0.86$ to 2.20$)$ & \\
\hline Vomiting $(n=4)$ & $53(16.1)$ & $92(9.2)$ & 1.90 (1.31 to 2.74$)$ & 1.55 (0.78 to 3.03 ) \\
\hline Measured temperature and fever $>38^{\circ} \mathrm{C}(\mathrm{n}=0)$ & $25(7.5)$ & $68(6.8)$ & $1.11(0.69$ to 1.80$)$ & \\
\hline Attended doctor $(n=47)$ & $102(32.2)$ & $323(33.3)$ & $0.90(0.69$ to 1.19$)$ & \\
\hline \multicolumn{5}{|l|}{ In the last day } \\
\hline Runny nose $(n=11)$ & $77(23.4)$ & $238(24.0)$ & 0.97 (0.72 to 1.3 ) & \\
\hline Cough $(n=7)$ & $35(10.6)$ & $126(12.7)$ & $0.82(0.55$ to 1.23$)$ & \\
\hline Diarrhoea $(n=13)$ & $14(4.3)$ & $18(1.8)$ & 2.45 (1.19 to 5.05$)$ & $1.47(0.36$ to 5.97$)$ \\
\hline Vomiting $(n=7)$ & $21(6.4)$ & $33(3.3)$ & 2.06 (1.15 to 3.70$)$ & $1.28(0.39$ to 4.16$)$ \\
\hline Measured temperature and fever $>38^{\circ} \mathrm{C}(\mathrm{n}=0)$ & $6(1.8)$ & $14(1.4)$ & $1.30(0.49$ to 3.44$)$ & \\
\hline \multicolumn{5}{|l|}{ Illnesses in the last $\mathbf{4}$ weeks (from paediatrician) } \\
\hline Common childhood infectious illnesses $(n=96)$ & $4(1.3)$ & $10(1.1)$ & $1.03(0.32$ to 3.33$)$ & \\
\hline URTI or bronchitis $(n=99)$ & $65(21.7)$ & $187(20.1)$ & 1.09 (0.78 to 1.51$)$ & \\
\hline Any other infection $(n=97)$ & 49 (16.3) & $116(12.4)$ & 1.40 (0.97 to 2.03$)$ & \\
\hline Any illness $(n=95)$ & $117(39.0)$ & $353(37.7)$ & $1.10(0.84$ to 1.44$)$ & \\
\hline \multicolumn{5}{|l|}{ Ever had the following (from paediatrician) } \\
\hline Developmental problems $(n=96)$ & $65(21.7)$ & $78(8.3)$ & 3.35 (2.25 to 4.97$)$ & 2.14 (1.04 to 4.39$)$ \\
\hline Accident $(n=95)$ & $9(3.0)$ & $22(2.4)$ & 1.11 (0.51 to 2.43$)$ & \\
\hline Neglect $(n=104)$ & $18(6.1)$ & $7(0.8)$ & 7.49 (3.12 to 17.93 ) & $0.79(0.21$ to 2.98$)$ \\
\hline Abuse suspected ( $n=102$ ) & $3(1.0)$ & $1(0.1)$ & - & \\
\hline Special investigations (e.g. $x$ ray, ECG) $(n=108)$ & $72(24.6)$ & $180(19.4)$ & $1.41(1.02$ to 1.95$)$ & 2.07 (1.18 to 3.64$)$ \\
\hline Laboratory test $(n=114)$ & $63(21.2)$ & $170(18.5)$ & $0.83(0.59$ to 1.15$)$ & \\
\hline Referred to other specialist $(n=97)$ & $93(31.1)$ & $274(29.3)$ & $1.17(0.87$ to 1.57$)$ & \\
\hline \multicolumn{5}{|l|}{ Hospital admission and outpatient clinic (OPC) data } \\
\hline Admitted to hospital at any stage of life $(n=36)$ & $113(34.7)$ & $157(16.2)$ & $2.88(2.12$ to 3.90$)$ & 1.26 (0.52 to 3.03$)$ \\
\hline $\begin{array}{l}\text { Admitted neonatal unit/hospital in first } 7 \text { days of life } \\
(n=36)\end{array}$ & $77(23.6)$ & $96(9.9)$ & 2.89 (2.05 to 4.08$)$ & $1.77(0.87$ to 3.62$)$ \\
\hline $\begin{array}{l}\text { Admitted to hospital, excluding admissions in first } \\
7 \text { days of life }(n=36)\end{array}$ & $53(16.3)$ & $75(7.7)$ & 2.31 (1.57 to $3 ., 41)$ & 1.88 (1.16 to 3.03 ) \\
\hline $\begin{array}{l}7 \text { days of life }(n=36) \\
\text { OPC or specialist clinic attendance }(n=0)\end{array}$ & $28(8.4)$ & $52(5.2)$ & $1.72(1.05$ to 2.82$)$ & \\
\hline Admitted to hospital for respiratory infection after the & $16(4.8)$ & $19(1.9)$ & $1.95(0.49$ to 7.69$)$ & \\
\hline first 7 days of life $(n=0)$ & & & & \\
\hline
\end{tabular}

the previous seven days did not differ between cases and controls.

Illness in the last four weeks as reported by the paediatrician did not differ between cases and controls. Developmental problems at any stage of life significantly increased the risk of SIDS (adjusted OR $=2.14$ ). Having had a special investigation, such as $x$ ray examination or electrocardiogram, was associated with an increased risk (adjusted OR $=2.07$ ).

Admission to hospital at any stage of life was associated with an increased risk of SIDS in the univariate analysis only, and this appeared to be predominantly after the first week of life $($ adjusted OR $=1.88)$.

\section{DISCUSSION}

This study is the first to report detailed analysis of symptoms and healthcare utilisation in the post "Back to Sleep" era. In this study just $4 \%$ of the control population sleep prone. Parental reported symptoms were common in cases and controls, and no symptom was associated with an increased risk of SIDS after adjustment for potential confounders. Paediatrician reported illness in the previous four weeks was not associated with SIDS. It has been reported that although the prevalence of respiratory symptoms does not differ, SIDS infants are sicker than the controls. ${ }^{10}$ The presence of documented fever is a good marker for severity of illness, but this did not differ between cases and controls.

Having had a special investigation was associated with SIDS, and this may reflect the fact that SIDS cases were more likely to have been admitted to hospital than controls. There were many different causes for the admission to hospital, and no specific causes, such as infection of the respiratory tract, appeared different.

These findings tend to support our hypothesis that symptoms of infection as a risk factor for SIDS are much less important now that few infants sleep prone.

Of interest was the observation that paediatrician reported presence of developmental problems was a risk factor for SIDS. This provides support for the contention that infants which subsequently succumb to SIDS may be abnormal or vulnerable in some way. However, it should be noted that the number of SIDS cases with developmental problems is only $22 \%$, and thus this is not a useful screening test for infants at risk of SIDS.

Limitations with this study should be recognised. Data obtained from the parents are subject to recall bias. However, it can reasonably be assumed that parents of cases might over-report symptoms, which would tend to increase the risk associated with symptoms. The fact that symptoms did not differ markedly between cases and controls provides support for our contention that symptoms of infection are no longer important as a risk factor for SIDS.

The second limitation is that standardised definitions for illness and health problems were not used by paediatricians, so that different criteria would have been used or the problem was not recognised. Although the paediatrician would most likely have used the child's medical records to help complete their questionnaire, what they wrote on the 
questionnaire could possibly be influenced by their knowledge of whether the subject was a case or control. Again this is more likely to increase the "identification" of illnesses and health problems among the cases. However, any such effect was likely to be small as only developmental problems were associated with an increased risk.

We conclude that symptoms of infection and illnesses are no longer risk factors for SIDS in communities such as Germany where few infants sleep prone, although admission to hospital for any cause was greater in cases than controls.

\section{ACKNOWLEDGEMENTS}

GeSID study group included: P Bach, B Bockholt, M Bohnert, U Cremer, U Deml, A Freislederer, S Heide, W Huckenbeck, K Jachau, H-J Kaatsch, A Klein, WJ Kleemann, K-P Larsch, A Fiegut, D Fischer, W Leukel, E Rauch, W Paulus, R Penning, F Rublack, C Sauerland, M Schlaud, B Schmidt, J Sperhake, G Zimmer, R Zweihoff.

\section{Authors' affiliations}

M M T Vennemann, Institute of Epidemiology and Social Medicine, University of Münster, Germany

M Findeisen, Westphalian Hospital for Children's and Youth Psychiatry, Marl, Germany

T Butterfaß-Bahloul, Coordinating Centre for Clinical Trials, University of Münster, Germany

G Jorch, Children's Hospital, University of Magdeburg, Germany

B Brinkmann, Institute for Legal Medicine, University of Münster, Germany

W Köpcke, Department of Medical Informatics and Biomathematics, University of Münster, Germany

T Bajanowski, A Richter, Institute for Legal Medicine, University of Duisburg-Essen, Germany
E A Mitchell, Department of Paediatrics, University of Auckland, New Zealand

Funding: The German Federal Ministry for Science and Education supported this study on Sudden Infant Death Syndrome from 1998 to 2003. Professor Ed Mitchell is supported by the Child Health Research Foundation, New Zealand.

Competing interests: none declared

\section{REFERENCES}

1 Werne J, Garow I. Sudden apparently unexplained death during infancy. I. Pathologic findings in infants found dead. Am J Pathol 1953;29:633-75

2 Bajanowski T, Wiegand P, Cecchi R, et al. Detection and significance of adenoviruses in cases of sudden infant death. Virchows Arch 1996;428:113-18.

3 Zink P, Drescher J, Verhagen W, et al. Serological evidence of recent influenza virus $A(H 3 N 2)$ infections in forensic cases of the sudden infant death syndrome (SIDS). Arch Virol 1987;93:223-32.

4 Gilbert R, Rudd P, Berry PJ, et al. Combined effect of infection and heavy wrapping on the risk of sudden unexpected infant death. Arch Dis Child 1992:67:171-7.

5 Ponsonby AL, Dwyer T, Gibbons LE, et al. Factors potentiating the risk of sudden infant death syndrome associated with the prone position. NEngl J Med 1993;329:377-82.

6 Findeisen M, Vennemann M, Brinkmann B, et al. German study on sudden infant death (GeSID): design, epidemiological and pathological profile. Int J Legal Med 2004;1 18:163-9.

7 Vennemann M, Findeisen M, Bajanowski T, et al. Modifiable risk factors for SIDS in Germany, results of GeSID. Acta Paediatr. In press.

8 Schlesselmann JJ, et al. Case-control studies: design, conduct, analysis. Oxford: Oxford University Press, 1982:269-90.

9 Taylor EM, Emery JL. Categories of preventable unexpected infant deaths. Arch Dis Child 1990;65:535-9.

10 Ford RPK, Mitchell EA, Stewart AW, et al. SIDS, illness, and acute medical care. Arch Dis Child 1997;77:54-5.

\title{
Working in paediatrics and not a member of the Royal College of Paediatrics
} and Child Health?

\author{
Have you thought about the benefits of joining? \\ Benefits and entitlements of membership \\ - Regular mailings including quarterly newsletter \\ - Listed in handbook plus your own copy at no extra charge \\ - Representation on Council (the College's governing body) \\ - Local support \\ - Archives of Disease in Childhood (BMJ cost to non members £206.00) \\ - Discount at Spring meeting \\ - Book club with discounts on books related to paediatrics \\ - CPD monitoring (fellows and associates) \\ - Voting at general meetings (fellows and ordinary members) \\ - Membership certificate (fellows and ordinary members) \\ - HST monitoring (ordinary members) \\ - Designation MRCPCH (ordinary members) \\ - Designation FRCPCH (fellows)
}

\author{
Subscriptions (inclusive of Archives) \\ Junior $\quad £ 140.00$ \\ Ordinary $\quad £ 325.00$ \\ Fellow $\quad £ 380.00$ \\ Associate $\quad £ 238.00$
}

Concessionary subscriptions are available for those working part time or resident overseas.

Application forms and information on eligibility are available via www.rcpch.ac.uk or by contacting The Membership Section, Royal College of Paediatrics and Child Health, 50 Hallam Street, London WIW 6DE; tel (020) 7307 5619/20/23; fax (020) 7307 5601; email: membership@rcpch.ac.uk. 